\title{
Identification of conformational epitopes for human IgG on Chemotaxis inhibitory protein of Staphylococcus aureus Erika Gustafsson* ${ }^{* 1,2,3}$, Pieter-Jan Haas ${ }^{\dagger 4}$, Björn Walse ${ }^{5}$, Marcel Hijnen ${ }^{6}$, Christina Furebring ${ }^{2}$, Mats Ohlin ${ }^{3}$, Jos AG van Strijp ${ }^{4}$ and Kok PM van Kessel ${ }^{4}$
}

\begin{abstract}
Address: ${ }^{1}$ Alligator Bioscience AB, Scheelev. 19A, S-223 70 Lund, Sweden, ${ }^{2}$ Alligator Bioscience AB, S-223 70 Lund, Sweden, ${ }^{3}$ Department of Immunotechnology, Lund University, BMC D13, S-221 84 Lund, Sweden, ${ }^{4}$ Medical Microbiology, University Medical Center Utrecht, 3584 CX Utrecht, the Netherlands, ${ }^{5}$ SARomics AB, S-220 07 Lund, Sweden and ${ }^{6}$ Macfarlane Burnet Institute for Medical Research and Public Health, Melbourne, Victoria 3004, Australia
\end{abstract}

Email: Erika Gustafsson* - erg@alligatorbioscience.com; Pieter-Jan Haas - P.J.A.Haas@umcutrecht.nl; Björn Walse - bjorn.walse@saromics.com; Marcel Hijnen - marcel@burnet.edu.au; Christina Furebring - chf@alligatorbioscience.com; Mats Ohlin - Mats.Ohlin@immun.lth.se; Jos AG van Strijp - J.vanStrijp@umcutrecht.nl; Kok PM van Kessel - K.Kessel@umcutrecht.nl

* Corresponding author †Equal contributors

Published: II March 2009

BMC Immunology 2009, 10:13 doi:10.1186/147|-2172-10-13

Received: 10 November 2008

Accepted: II March 2009

This article is available from: http://www.biomedcentral.com/I47I-2/72/I0/13

(c) 2009 Gustafsson et al; licensee BioMed Central Ltd.

This is an Open Access article distributed under the terms of the Creative Commons Attribution License (http://creativecommons.org/licenses/by/2.0), which permits unrestricted use, distribution, and reproduction in any medium, provided the original work is properly cited.

\begin{abstract}
Background: The Chemotaxis inhibitory protein of Staphylococcus aureus (CHIPS) blocks the Complement fragment $\mathrm{C} 5 \mathrm{a}$ receptor (C5aR) and formylated peptide receptor (FPR) and is thereby a potent inhibitor of neutrophil chemotaxis and activation of inflammatory responses. The majority of the healthy human population has antibodies against CHIPS that have been shown to interfere with its function in vitro. The aim of this study was to define potential epitopes for human antibodies on the CHIPS surface. We also initiate the process to identify a mutated CHIPS molecule that is not efficiently recognized by preformed anti-CHIPS antibodies and retains anti-inflammatory activity.

Results: In this paper, we panned peptide displaying phage libraries against a pool of CHIPS specific affinity-purified polyclonal human lgG. The selected peptides could be divided into two groups of sequences. The first group was the most dominant with 36 of the 48 sequenced clones represented. Binding to human affinity-purified IgG was verified by ELISA for a selection of peptide sequences in phage format. For further analysis, one peptide was chemically synthesized and antibodies affinity-purified on this peptide were found to bind the CHIPS molecule as studied by ELISA and Surface Plasmon Resonance. Furthermore, seven potential conformational epitopes responsible for antibody recognition were identified by mapping phage selected peptide sequences on the CHIPS surface as defined in the NMR structure of the recombinant CHIPS $_{31-121}$ protein. Mapped epitopes were verified by in vitro mutational analysis of the CHIPS molecule. Single mutations introduced in the proposed antibody epitopes were shown to decrease antibody binding to CHIPS. The biological function in terms of C5aR signaling was studied by flow cytometry. A few mutations were shown to affect this biological function as well as the antibody binding.

Conclusion: Conformational epitopes recognized by human antibodies have been mapped on the CHIPS surface and amino acid residues involved in both antibody and C5aR interaction could be defined. This information has implications for the development of an effective anti-inflammatory agent based on a functional CHIPS molecule with low interaction with human lgG.
\end{abstract}




\section{Background}

Chemotaxis inhibitory protein of Staphylococcus aureus (CHIPS) is a potent inhibitor of neutrophil chemotaxis and activation by specifically binding and blocking the Gprotein coupled Complement fragment $\mathrm{C} 5 \mathrm{a}$ receptor $(\mathrm{C} 5 \mathrm{aR})$ and formylated peptide receptor (FPR) $[1,2]$. C5a is a complement polypeptide with many functions. It exerts pro-inflammatory effects through the $\mathrm{C} 5 \mathrm{aR}$ and is involved in host defense against microorganisms. The $\mathrm{C} 5 \mathrm{a} / \mathrm{C} 5 \mathrm{aR}$ interaction mediates immunomodulatory and inflammatory activities such as chemotaxis, degranulation, vascular permeabilisation and cytokine regulation [3-6]. C5a plays a role in a wide variety of inflammatory disorders like rheumatoid arthritis, inflammatory bowel disease, immune complex disease, ischemia-reperfusion injury and sepsis [7-13]. Since C5a is generated early in the inflammatory cascade it is a promising target for antiinflammatory therapy. Several studies have demonstrated the beneficial effects of targeting the C5aR in inflammatory diseases [14-19].

The potent ability of CHIPS to inhibit activation of the $\mathrm{C} 5 \mathrm{aR}$ is an important asset which might be useful for development of a potential new anti-inflammatory drug. However, since the CHIPS gene is present in over $60 \%$ of Staphylococcus aureus strains and S. aureus is a common bacterium, a majority of the population encounters CHIPS early in life. Human serum contains anti-CHIPS antibodies that have been shown to interfere with CHIPS function in vitro [20]. These antibodies may therefore neutralize the in vivo effect of CHIPS or give rise to antibody mediated immune reactions. As such, the potential of CHIPS to function as an anti-inflammatory molecule is hampered. An improved CHIPS molecule will be characterized by decreased reactivity with pre-existing antibodies, but preserved C5aR blocking activity. Mapping the epitopes of human IgG on the CHIPS protein is an important step in the understanding of how antibodies interfere with CHIPS.

Antibody screening of phage-displayed peptide libraries is a useful approach to identify antibody epitopes [21,22]. Previous studies showed the potential of using random peptide phage libraries in identifying linear epitopes and conformational epitopes for monoclonal and polyclonal antibodies. For example, Luzzago et al. identified discontinuous epitopes in human H-subunit ferritin by the use of phage display and verified the potential epitopes by design of variants with point mutations [23]. Rowley et al. studied autoantibodies in primary biliary cirrhosis and could predict the major conformational antibody epitope using phage display and the known NMR structure of the target protein [24]. These studies show that peptides expressed by phage display are capable of adopting a conformation that mimics the epitopes.
In this paper we focus on mapping epitopes on CHIPS by panning of phages displaying 7 -mer peptides against polyclonal human IgG affinity-purified on $\mathrm{N}$ - and C-terminally truncated CHIPS. Peptides selected by phage display could be grouped into two distinct groups based on their sequence. These were then verified in ELISA and by the use of a synthetic peptide. By mapping the selected peptide sequences on the CHIPS surface using the known NMR structure of CHIPS $_{31-121}$ [25], potential conformational epitopes for human IgG could be identified. The epitopes were subsequently verified by mutation of key amino acids in the CHIPS molecule and the activity of the mutants was studied by C5aR inhibition. The mutational analysis of the epitopes revealed amino acid residues that are important for the interaction of CHIPS with human antibodies. In addition, amino acids involved in the interaction with the C5aR were identified.

\section{Results \\ Truncated CHIPS variants inhibit C5a induced cell activation}

In order to isolate a small active CHIPS variant able to form a functional molecule with decreased number of antibody epitopes, we generated truncated variants of CHIPS. Previously, we described CHIPS with N-terminal truncation $(\Delta \mathrm{N})[25]$ and CHIPS with both $\mathrm{N}$ - and C-terminal truncations $(\Delta \mathrm{N} / \mathrm{C})[26]$ that showed a complete preservation of $\mathrm{C} 5 \mathrm{aR}$ blocking activity. Figure 1 summarizes the activity of different CHIPS variants (CHIPS $\Delta \mathrm{N}$, CHIPS $\Delta \mathrm{C}$ and CHIPS $\Delta \mathrm{N} / \mathrm{C}$ in comparison to full-length

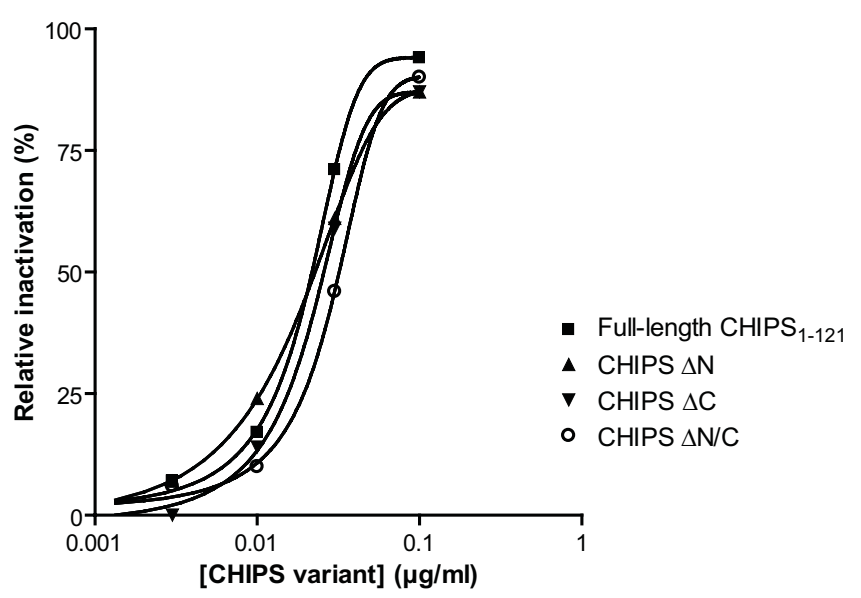

Figure I

Truncated CHIPS variants inhibit $\mathrm{C5a}$ induced cell activation. Fluo-3AM labeled U937/C5aR transfectants were preincubated with full-length CHIPS ${ }_{|-12|}$, CHIPS with $\mathrm{N}$-terminal truncation (CHIPS $\Delta \mathrm{N}$ ), CHIPS with C-terminal truncation (CHIPS $\triangle \mathrm{C}$ ) and CHIPS with truncations in both the $\mathrm{N}$ - and $\mathrm{C}$-terminal ends (CHIPS $\Delta \mathrm{N} / \mathrm{C}$ ) and stimulated with I nM C5a. Results are expressed as percentage inhibition of buffer treated cells and are from a representative experiment. 
CHIPS $_{1-121}$. All truncated CHIPS variants were able to inhibit the C5a induced activation of U937/C5aR cells to the same extent as full-length wild-type (wt) CHIPS $_{1-121}$. Hence, the smallest CHIPS variant tested, a molecule with preserved biological activity with truncations in both the $\mathrm{N}$ - and C-terminal end (resulting in a protein of 83 amino acids) was used for further studies. This CHIPS variant has most likely lost the ability to block activation of the FPR, since the N-terminal amino acids of CHIPS are required for that action [27].

\section{Affinity-purified anti-CHIPS antibodies recognize non- linear epitopes}

In order to map antibody epitopes on CHIPS, affinity purification of human anti-CHIPS IgG was initially performed on the wt CHIPS ${ }_{1-121}$ protein. Pooled human IgG (IV-IgG) was affinity-purified using a column packed with immobilized CHIPS $_{1-121}$ resin. We tested the binding of affinity-purified anti-CHIPS ${ }_{1-121}$ antibodies to a set of CHIPS derived 25-mer peptides spanning the complete CHIPS $_{1-121}$ sequence. As shown in Figure 2A, linear epitopes do appear to be confined to the $\mathrm{N}$-terminus of CHIPS. To confirm the presence of conformational epitopes, we tested the reactivity of two different affinitypurified antibody preparations (anti-full-length CHIPS 1- $_{\text {- }}$ ${ }_{121}$ and anti-CHIPS $\Delta \mathrm{N} / \mathrm{C}$ ) to wt CHIPS $_{1-121}$, CHIPS $\Delta \mathrm{N}$ and CHIPS $\triangle$ N/C. Figure $2 \mathrm{~B}-\mathrm{D}$ shows that both preparations of affinity isolated antibodies react with all three CHIPS variants. There is no significant difference in reactivity towards the different CHIPS variants between the preparations. Reactivity of the different CHIPS variants with the control antibody 2G8 (a monoclonal mouse anti-CHIPS antibody [27]) was also comparable, indicating that all CHIPS variants coated equally well. These data also imply that epitopes outside the N-terminus may be of importance for antibody binding and that some of these epitopes are conformational.

\section{Panning experiments identified potential antibody recognition sequences}

To obtain peptides mimicking epitopes other than the linear epitopes found in the N-terminus of CHIPS, two random peptide phage libraries were screened for binding to anti-CHIPS $\Delta \mathrm{N} / \mathrm{C}$ IgG. The starting material was a mixture of two different libraries (PhD-7 displaying linear peptides and PhD-C7C displaying cyclic peptides). After four rounds of panning, 48 recombinant phage clones were randomly selected and characterized by DNA sequencing. The sequence 'MNKTWYP' occurred 12 times among the sequenced clones and was thereby the most abundant followed by 'MNKTFWF' which was selected five times. A majority of the selected peptides (42 of 48) could be divided into two different groups based on their amino acid sequence as shown in Table 1 . Amino acids that occurred most frequently among the aligned sequences for each group were classified as consensus residues. 36 sequences belonged to the first group and their consensus sequence was defined as 'MNKT/Sxxx'. Six sequences with the consensus sequence 'GKLPxxx' belonged to the second group. Although we started out with a mixture of two different libraries (PhD-7 and PhD-C7C) with linear and circular peptides displayed, respectively, the selected sequences were all originating from the PhD-7 library with linear sequences. Six different recombinant phages expressing representative peptide sequences were characterized in ELISA for binding to human anti-CHIPS $\Delta \mathrm{N} / \mathrm{C}$ IgG. These phages bound specifically to the antibodies and not to BSA (Figure 3). We therefore conclude that the binding of the selected phages to affinity-purified human anti-CHIPS $\Delta \mathrm{N} / \mathrm{C}$ IgG is specific for the expressed peptide.

\section{Synthetic peptides can be used to purify CHIPS specific antibodies}

To investigate the specificity of antibodies purified on the selected peptides, a synthetic peptide from the group 1 consensus sequence (MNKSYTI) was synthesized. As the $\mathrm{N}$-terminus of CHIPS was shown to contain linear epitopes for human antibodies, a N-terminal peptide (aa 1-38) of CHIPS was used for comparison. The synthesized peptides were designed to contain a C-terminal cysteine residue that allowed immobilization by thiol coupling chemistry. They were subsequently coupled to activated Sepharose to create affinity columns, which were used to capture peptide-specific antibodies from the human polyclonal IgG pool (IV-IgG). Binding of the affinity-purified anti-peptide antibodies to the CHIPS $_{1-121}$ molecule was studied by ELISA and Surface Plasmon Resonance (SPR) (Figure 4). The affinity-purified anti-group 1 peptide antibodies, the anti-CHIPS $\Delta \mathrm{N} / \mathrm{C}$ antibodies as well as affinity-purified anti-1-38 peptide antibodies were found to bind to the native CHIPS ${ }_{1-121}$ protein in ELISA and SPR. Preincubation with CHIPS ${ }_{1-121}$ abolished this binding. Without affinity purification, the same concentration of IV-IgG showed no detectable binding.

\section{Potential antibody epitopes were identified on the CHIPS surface}

To identify potential antibody epitopes, the consensus sequences 'MNKT/Sxxx' and 'GKLPxxx', were manually mapped onto the surface of CHIPS $_{31-121}$ by structural analysis. The fold of N-terminally truncated CHIPS consists of an N-terminal amphipathic $\alpha$-helix and a fourstranded anti-parallel $\beta$-sheet as determined by multidimensional NMR [25]. The structure of CHIPS with Cterminal truncation is not yet determined, consequently the available NMR structure was used for mapping of the epitopes. More specifically, the suggested epitopes are composed of adjacent amino acids found in the 3D structure (or amino acids with similar chemical properties to those in the consensus sequences).

In total, seven different mapping possibilities of the two consensus sequences were identified. These are denoted Surface 1.1-1.6 and 2.1 (Table 2). Residue-residue dis- 
A

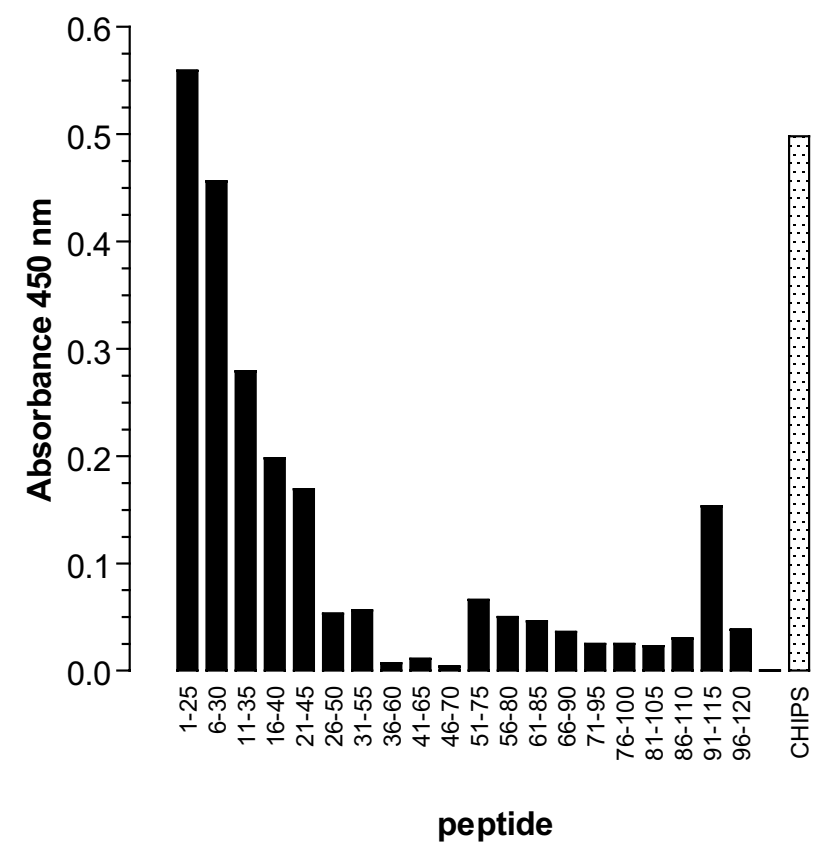

C

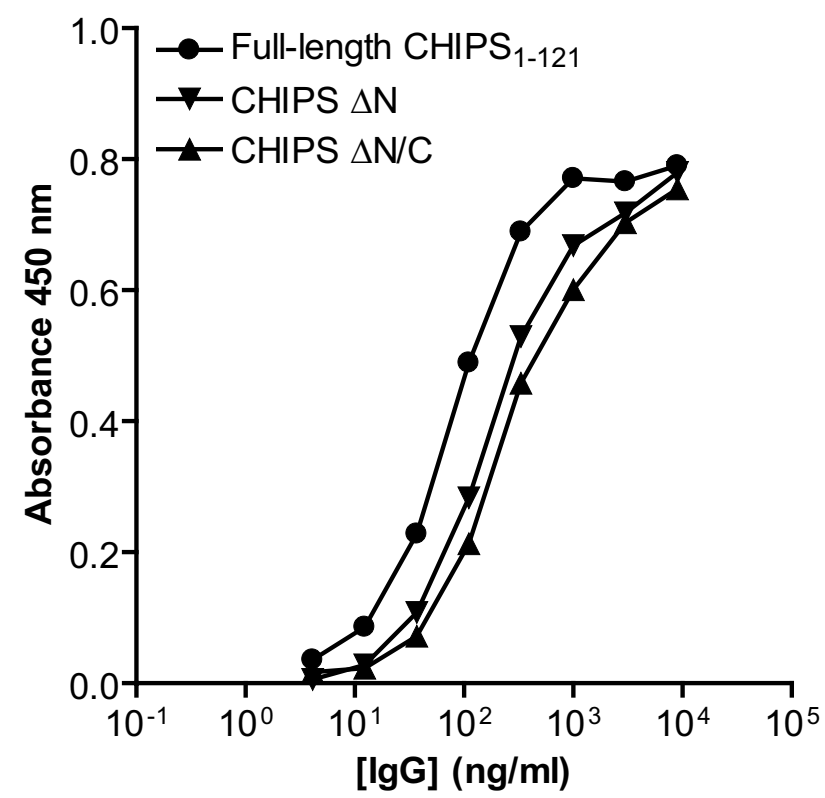

B

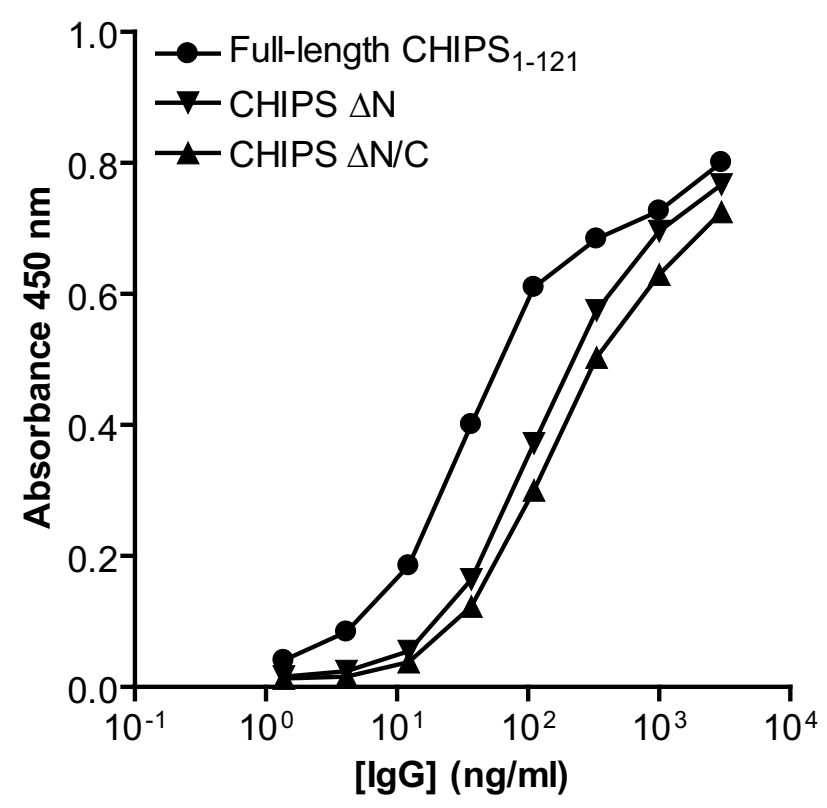

D

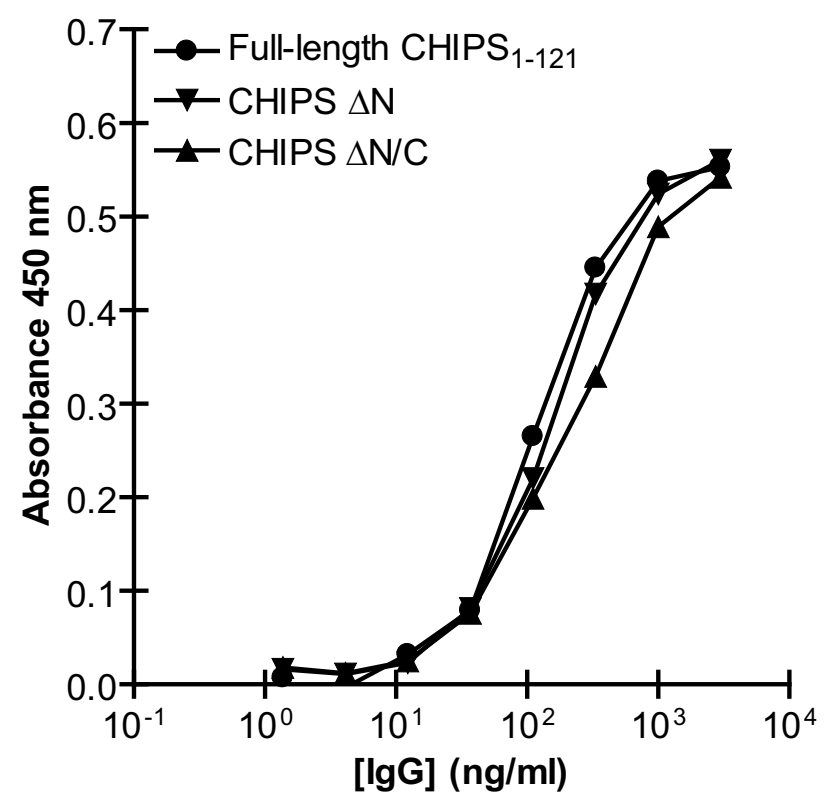

Figure 2

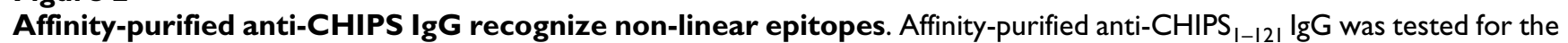
ability to bind CHIPS derived 25-mer peptides or full-length CHIPS in ELISA (A). Full-length CHIPS I-121 $_{\text {or }}$ CHIPS with N-terminal truncation (CHIPS $\triangle \mathrm{N}$ ), or CHIPS with truncations in both the $\mathrm{N}$ - and $\mathrm{C}$-terminal ends (CHIPS $\triangle \mathrm{N} / \mathrm{C}$ ) were compared for reactivity with different human affinity-purified anti-full-length $\mathrm{CHIPS}_{|-| 2 \mid} \lg \mathrm{g}(\mathrm{B})$, anti-CHIPS $\triangle N / C \lg \mathrm{C}(\mathrm{C})$, and the CHIPS specific mouse monoclonal antibody $2 \mathrm{G} 8$ as control (D). 
Table I: Selected phage peptide sequences were divided into two groups based on their amino acid sequences*.

\begin{tabular}{|c|c|c|c|c|c|c|c|c|}
\hline Group I & $M$ & $\mathbf{N}$ & $\mathbf{K}$ & $\mathbf{T} / \mathbf{S}$ & $\mathbf{x}$ & $x$ & $\mathbf{x}$ & Frequency \\
\hline & $M$ & $N$ & $\mathrm{~K}$ & $T$ & W & $Y$ & $P$ & $(12)$ \\
\hline & $M$ & $\mathrm{~N}$ & $\mathrm{~K}$ & $\mathrm{~T}$ & $\mathrm{~F}$ & W & $\mathrm{F}$ & (5) \\
\hline & $M$ & $\mathrm{~N}$ & $\mathrm{~K}$ & $\mathrm{~T}$ & $\mathrm{~F}$ & $\mathrm{~F}$ & $S$ & (2) \\
\hline & $M$ & $\mathrm{~N}$ & $\mathrm{~K}$ & $\mathrm{~S}$ & $Y$ & $\mathrm{H}$ & $\mathrm{L}$ & (2) \\
\hline & $M$ & $\mathrm{~N}$ & $\mathrm{~K}$ & $\mathrm{~T}$ & $\mathrm{~F}$ & $S$ & A & (I) \\
\hline & $M$ & $\mathrm{~N}$ & $\mathrm{~K}$ & $\mathrm{~T}$ & $\mathrm{~F}$ & V & $D$ & (I) \\
\hline & $M$ & $\mathrm{~N}$ & $\mathrm{~K}$ & $\mathrm{~T}$ & $\mathrm{~F}$ & V & $\mathrm{P}$ & (I) \\
\hline & $M$ & $\mathrm{~N}$ & $\mathrm{~K}$ & V & $Y$ & $\mathrm{~L}$ & $P$ & (I) \\
\hline & $M$ & $\mathrm{~N}$ & $\mathrm{~K}$ & $S$ & $Y$ & $\mathrm{~T}$ & 1 & (I) \\
\hline & $M$ & $N$ & $\mathrm{~K}$ & $Y$ & $\mathrm{H}$ & $N$ & $P$ & (I) \\
\hline & $\mathrm{F}$ & $N$ & $\mathrm{~K}$ & $S$ & $Y$ & $Y$ & G & (3) \\
\hline & $Y$ & $\mathrm{~N}$ & $\mathrm{~K}$ & $S$ & $\mathrm{~F}$ & $\mathrm{~F}$ & $M$ & (2) \\
\hline & $Y$ & $\mathrm{~N}$ & $\mathrm{~K}$ & $S$ & $\mathrm{~F}$ & $\mathrm{~F}$ & $P$ & (I) \\
\hline & $\mathrm{F}$ & $\mathrm{N}$ & $\mathrm{K}$ & $S$ & W & $\mathrm{F}$ & $P$ & (I) \\
\hline & $\mathrm{L}$ & $\mathrm{N}$ & $\mathrm{K}$ & $T$ & $\mathrm{~F}$ & $Y$ & $Y$ & (I) \\
\hline & $\mathrm{V}$ & $N$ & $\mathrm{~K}$ & $\mathrm{~T}$ & $Y$ & W & K & (I) \\
\hline \multirow[t]{7}{*}{ Group 2} & G & $\mathbf{K}$ & $\mathbf{L}$ & $\mathbf{P}$ & $\mathbf{x}$ & $\mathbf{x}$ & $\mathbf{x}$ & \\
\hline & G & $\mathrm{K}$ & $\mathrm{L}$ & $P$ & I & $A$ & $M$ & (I) \\
\hline & G & $\mathrm{K}$ & $\mathrm{L}$ & $P$ & W & $P$ & $K$ & (I) \\
\hline & G & $\mathrm{K}$ & $\mathrm{L}$ & $P$ & 1 & $P$ & $Y$ & (I) \\
\hline & G & $\mathrm{K}$ & $\mathrm{L}$ & $P$ & $P$ & $P$ & I & (I) \\
\hline & G & $\mathrm{K}$ & L & $P$ & $\mathrm{~K}$ & $M$ & $\mathrm{~T}$ & (I) \\
\hline & $\mathrm{G}$ & $\mathrm{K}$ & $\mathrm{L}$ & $P$ & $\mathrm{~K}$ & $\mathrm{E}$ & $S$ & (I) \\
\hline
\end{tabular}

* A consensus sequence for each group was determined and is shown in bold. The frequency of each peptide is shown in parenthesis.

tances between $\mathrm{C} \alpha, \mathrm{C} \beta$ or the closest side chain atoms of the epitope were measured to verify that the amino acids building up the proposed epitopes were adjacent (See Additional files: Table 1).

Surfaces 1.1-1.4 are based on the Group 1 consensus sequence and are largely overlapping, differing only in one or two amino acids (Figure 5). Surface 1.5 and 1.6 are also based on the Group 1 consensus sequence, but they are situated in a different part of the protein and are composed of different amino acids. Only one mapping possibility was found for the Group 2 consensus sequence. This potential epitope (Surface 2.1) was situated on the opposite side of the CHIPS molecule as compared to Surfaces $1.1-1.4$.

\section{Verification of proposed surfaces by mutational analysis}

In an attempt to verify the proposed surfaces and their relation to antibody epitopes, a mutational strategy was applied. To produce mutants with key amino acids altered, point mutations (one per sequence) were introduced into the C-terminally truncated CHIPS sequence. The specific amino acid substitutions were designed to alter the suggested epitopes by substituting key amino acids to residues with different chemical properties or size. In addition, the specific amino acid substitutions
A

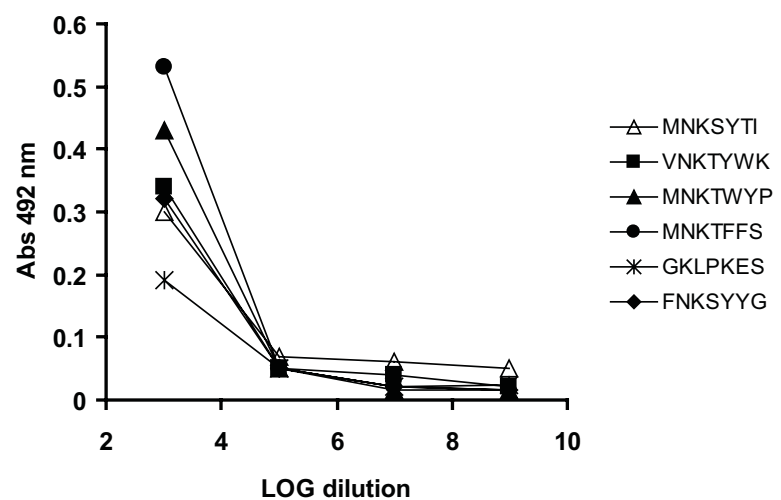

B

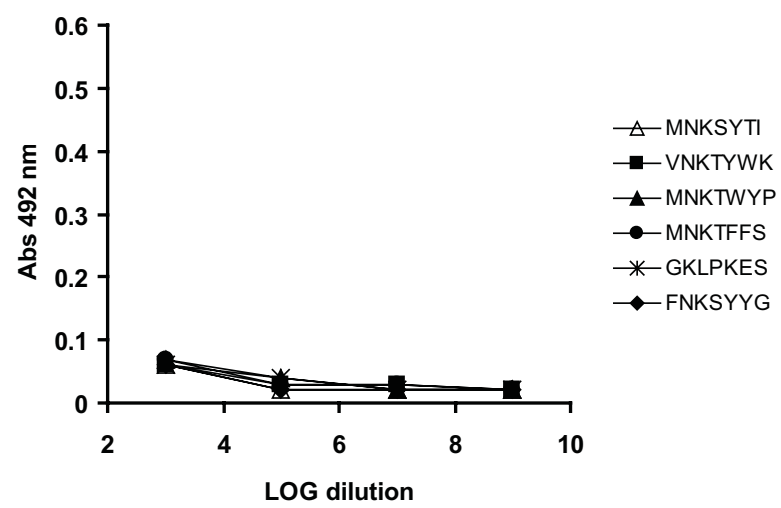

Figure 3

Selected phages bind human anti-CHIPS $\Delta$ N/C IgG in ELISA. Six different recombinant phages expressing representative peptide sequences were characterized in ELISA for binding to human anti-CHIPS $\triangle \mathrm{N} / \mathrm{C} \lg \mathrm{G}$. These phages were found to bind affinity-purified human anti-CHIPS $\triangle N / C \lg G$ (A) but not BSA (B).

were also chosen in a way not to destabilize the protein. Hence, similar amino acids have been substituted to different amino acid types depending on their location in the protein. However, not all amino acids were suitable for mutagenesis, as they were predicted to be important for preserving the structure of CHIPS. These amino acids, R46 [25] as well as Y72, L76 and Y108 (with side-chains protruding into the interior cavity of the protein), were therefore left unchanged.

The CHIPS mutants were characterized in a CHIPS capture ELISA for decreased binding of human anti-CHIPS $\Delta \mathrm{N} / \mathrm{C}$ IgG (Table 3) by making full titration curves of the mutants. The cut-off value for decreased binding was set to $90 \%$ of maximum binding of the wt C-terminally truncated CHIPS binding curve. 9 out of the 17 mutants showed a decreased reactivity with human anti-CHIPS $\Delta \mathrm{N} / \mathrm{C}$ IgG and are marked in bold in Table 3. Each of the seven mapped surfaces, defining potential conformational epitopes in CHIPS, involved one to three residues 
A

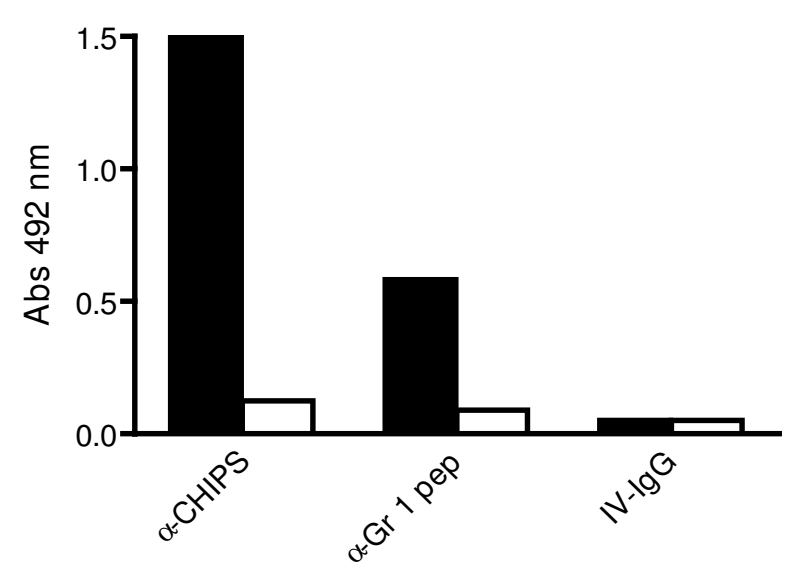

B

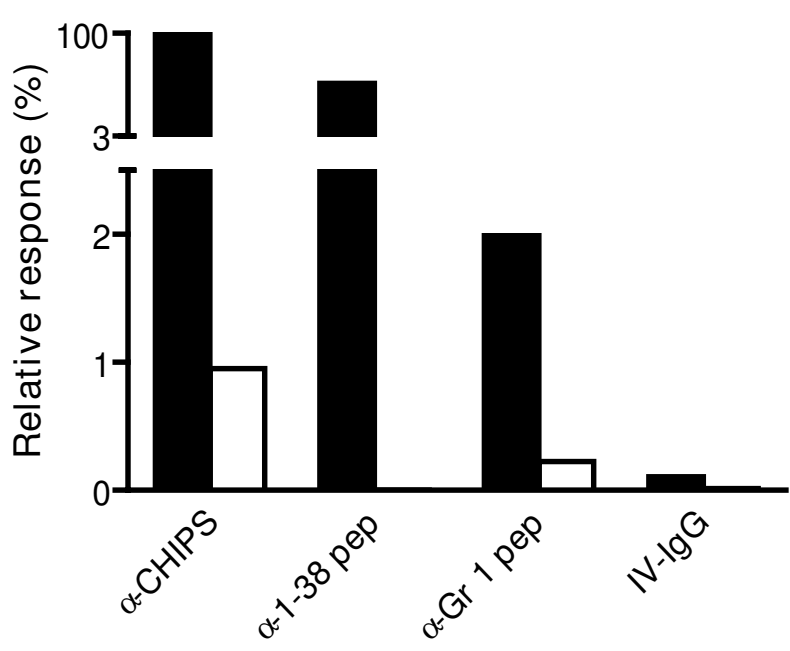

Figure 4

Synthetic peptides can be used to purify CHIPS specific antibodies. Binding of affinity-purified anti-CHIPS $\triangle N$ / C IgG (a-CHIPS), anti-group I peptide (a-Gr I pep) and IVIgG to immobilized CHIPS $_{|-| 2 \mid}$ were measured in ELISA (A) and SPR (B). Black bars represent binding of the different affinity-purified antibodies. White bars show binding of antibodies that were pre-incubated with $\mathrm{CHIPS}_{|-| 2 \mid}$.

that one by one were important for antibody binding. Residues K100, S107 and N55 were found to be involved in three suggested epitopes (K100 and S107: Surface 1.11.3) (N55: Surface 1.1, 1.2 and 1.4). Other amino acids found to be important for antibody binding were N68, K69, K92, K95, Y97 and N111. K69 was represented in both Surface 1.5 and 2.1, whilst the other residues were only represented in one of the proposed surfaces.
Table 2: Suggested anti-CHIPS $\Delta$ N/C IgG epitopes.

\begin{tabular}{|c|c|c|c|c|c|c|c|}
\hline Consensus group I & $M$ & $\mathbf{N}$ & $\mathbf{K}$ & $\mathbf{T} / \mathbf{S}$ & $\mathbf{x}$ & $\mathbf{x}$ & $\mathbf{x}$ \\
\hline Surface I.I & & N55 & $\mathrm{K} 100$ & T53 & S107 & Y 108 & \\
\hline Surface 1.2 & & N55 & $\mathrm{K} 100$ & SI07 & YI08 & & \\
\hline Surface 1.3 & & Q58 & $\mathrm{K} 100$ & S107 & Y108 & & \\
\hline Surface 1.4 & & N55 & K54 & T53 & YI08 & & \\
\hline Surface 1.5 & & N68 & K69 & G70 & Y7I & Y72 & \\
\hline Surface 1.6 & & NIII & K95 & Y94 & Y97 & Y7I & \\
\hline Consensus group 2 & G & $\mathbf{K}$ & $\mathbf{L}$ & $\mathbf{P}$ & $\mathbf{x}$ & $\mathbf{x}$ & $\mathbf{x}$ \\
\hline Surface 2.1 & & K69 & L90 & P35 & $\mathrm{K} 92$ & E67 & \\
\hline
\end{tabular}

New CHIPS variants can still block activation of the C5aR To investigate whether the selected new CHIPS variants with reduced antibody binding were still functional in preventing C5a induced activation of the C5aR, the 9 mutants were purified and analyzed in a calcium flux assay. Serial dilutions of the variants were preincubated with Fluo-3AM labeled U937/C5aR cells and the cells were stimulated with $1 \mathrm{nM}$ C5a. Flow cytometry data showed that mutants N55K, N68A, K69T, K92E and $\mathrm{N} 111 \mathrm{~K}$ retained full C5aR blocking activity at $1 \mu \mathrm{g} / \mathrm{ml}$. In contrast, Y97K completely abolished and K95S, K100A and S107N partially abolished the biological activity in comparison to wt C-terminally truncated CHIPS (Figure 6). Thus, some mutations that interfere with antibody binding are not compatible with biological function.

\section{Structural comparisons using circular dichroism spectroscopy (CD)}

The K95S, Y97K, K100A and S107N mutants showed reduced C5aR blocking activity. In order to ascertain if this reduced activity was due to mutation of $\mathrm{C} 5 \mathrm{aR}$ contacting residues and not major conformational changes compared to the structure of the corresponding wt, CD spectra for the new CHIPS variants were investigated. Even spectra of variants with decreased biological activity showed a significant absorption minimum at $205 \mathrm{~nm}$ similar to the corresponding wt. These introduced mutations consequently are unlikely to have affected the global fold of the molecule (Figure 7).

\section{Discussion}

Antibodies often react with tertiary structures formed through protein folding. In contrast to linear epitopes, these epitopes are formed when remote amino acids in the primary sequence of a protein are brought into close proximity in the folded protein, hence they are referred to as discontinuous or conformational epitopes. Antibody screening of phage-displayed peptide libraries is an efficient method to identify both linear and conformational epitopes [21,22]. Epitopes have been revealed both for 
1.1

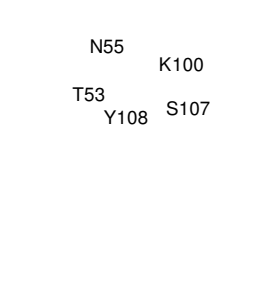

1.2

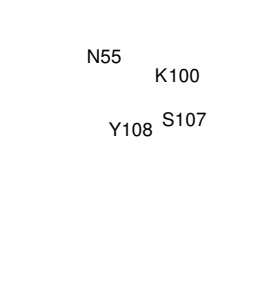

1.3

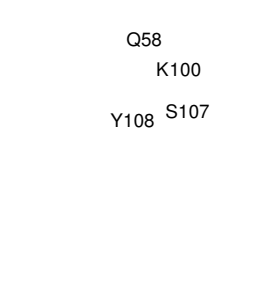

1.4

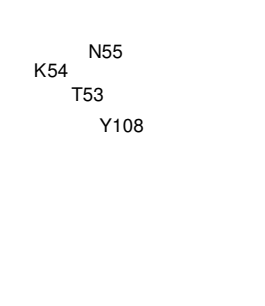

$90^{\circ}$

仓
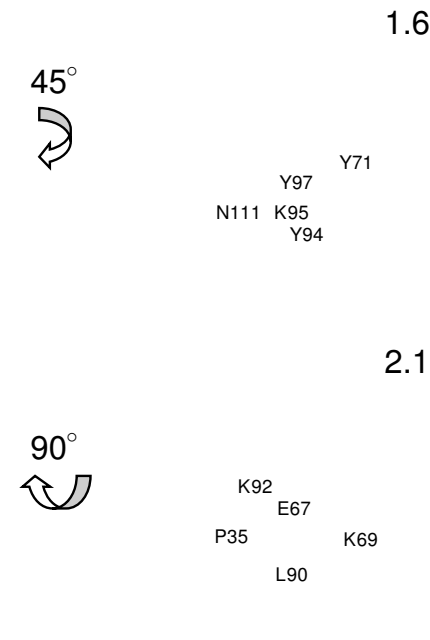

$20 \AA$

Figure 5

Conformational antibody epitopes in the $\mathrm{CHIPS}_{31-121}$ structure. Surface representation of $\mathrm{N}$-terminally truncated CHIPS (PDB code: IXEE) with potential conformational antibody epitopes shown in different colors; surface I.I (red), surface I.2 (orange), surface I.3 (magenta), surface I.4 (yellow), surface I.5 (blue), surface I.6 (green) and surface 2.I (cyan). Figures were generated by the PyMOL molecular graphics system [37].

monoclonal $[28,29]$ and polyclonal antibodies $[24,30,31]$. In this study, we used two phage-displayed random peptide libraries to map the epitopes for polyclonal human anti-CHIPS $\Delta \mathrm{N} / \mathrm{C}$ IgG on CHIPS. Phage selection depends on many factors, for instance, arginines in the displayed peptide sequence interfere with secretion of the coat protein pIII and consequently clones with peptides containing arginines are strongly selected against [32]. Furthermore, the stringency and nature of the wash steps can favor certain phages [33]. To increase the specif- icity of selected phages for binding to CHIPS IgG, we used competition elution with a high concentration of CHIPS in the last round of selection.

Peptides found to be involved in human anti-CHIPS $\Delta \mathrm{N} /$ $\mathrm{C}$ IgG binding all originated from the phage library which expressed linear peptides, and not from the library with cyclic peptides. We speculate that linear peptides might have been favorable in these selections since they may be able to adopt more conformations than the more rigid cyclic peptides. Mapping of the linear peptides obtained from phage selections with anti-CHIPS $\Delta \mathrm{N} / \mathrm{C}$ IgG identified seven potential epitope surfaces, out of which six represent conformational epitopes. This is in accordance with the result from the pepscan ELISA, where mainly peptides spanning the N-terminal part of CHIPS were recognized by anti-CHIPS IgG. Antibody binding to CHIPS is thus likely to be a combination of interaction with conformational and linear epitopes.

The interaction between an antibody and its epitope is dependent on several amino acid residues [34]. The nature of the amino acid substituted in a mutagenesis study can affect the ability to detect its involvement in the investigated epitope [35]. Here, we have substituted residues of the suggested epitopes by amino acids with different characteristics in an effort to detect the epitopes recognized by polyclonal anti-CHIPS $\Delta$ N/C IgG. Furthermore, single mutations are likely to affect the binding of only a fraction of all antibodies in a polyclonal preparation. Therefore, the effect of site-directed mutagenesis of a single residue may be difficult to detect by ELISA, as was found in this study. If the mutations mediating an effect on antibody binding were combined in one sequence they may have a synergistic effect to further decrease the antibody interaction with CHIPS.

Nevertheless, we were able to identify amino acid residues important for antibody interaction. By mutagenesis of residues in the different proposed surfaces, we retrieved information on which of the suggested surfaces were likely to be true epitopes. Surface 1.2 and 1.6 are the surfaces affected most by the mutagenesis. For surface 1.2, mutagenesis in three out of three positions resulted in lower interaction with the IgG. N55 in the loop between the $\alpha$-helix and $\beta 1$, K100 in the $\beta 3$ sheet and S107 located in the short loop between $\beta 3$ and $\beta 4$ were all shown to be involved in antibody interaction. Surface 1.6 contains two amino acids (K95 and Y97 in the $\beta 3$ sheet) that upon mutagenesis reduced the antibody binding to less than $50 \%$, respectively. N111, located in a well defined long loop between the $\beta 2$ and $\beta 3$ strands, was also shown to contribute to antibody binding. Surface 1.1-1.4 are overlapping structures. Surface 1.1, 1.3 and 1.4 were considered less likely to be true epitopes since mutagenesis of amino acids T53 in surface 1.1 and 1.4, Q58 in 1.3 as well as T53 and K54 in 1.4 
Table 3: Suggested anti-CHIPS $\triangle$ N/C IgG epitopes and amino acid substitutions that have been made to verify epitopes*.

\begin{tabular}{|c|c|c|c|c|c|c|c|}
\hline Consensus group I & $\mathbf{M}$ & $\mathbf{N}$ & $\mathbf{K}$ & $\mathbf{T} / \mathbf{S}$ & $\mathbf{x}$ & $\mathbf{x}$ & $\mathbf{x}$ \\
\hline Surface I.I & & N55K & KIOOA & T53G & SI07N & Y108 & \\
\hline mutations & & $86 \%$ & $78 \%$ & $93 \%$ & $76 \%$ & - & \\
\hline Surface 1.2 & & N55K & KIOOA & SI07N & YI08 & & \\
\hline mutations & & $86 \%$ & $78 \%$ & $76 \%$ & - & & \\
\hline Surface 1.3 & & Q58K & KIOOA & SI07N & Y108 & & \\
\hline mutations & & $90 \%$ & $78 \%$ & $76 \%$ & - & & \\
\hline Surface 1.4 & & N55K & $\mathrm{K} 54 \mathrm{R}$ & T53G & YI08 & & \\
\hline mutations & & $86 \%$ & $90 \%$ & $93 \%$ & - & & \\
\hline Surface 1.5 & & N68A & K69T & G70 & Y7I & Y72 & \\
\hline mutations & & $\mathbf{8 0} \%$ & $\mathbf{8 8} \%$ & - & $96 \%$ & - & \\
\hline Surface 1.6 & & NIIIK & K95S & $\mathrm{Y94H}$ & Y97K & Y7IK & \\
\hline mutations & & $78 \%$ & $47 \%$ & $97 \%$ & $49 \%$ & $96 \%$ & \\
\hline Consensus group 2 & G & $\mathbf{K}$ & $\mathbf{L}$ & $\mathbf{P}$ & $\mathbf{x}$ & $\mathbf{x}$ & $\mathbf{x}$ \\
\hline Surface 2.1 & & K69T & L90E & P35A & K92E & E67K & \\
\hline mutations & & $88 \%$ & $92 \%$ & $97 \%$ & $85 \%$ & $91 \%$ & \\
\hline
\end{tabular}

* The suggested epitopes are denoted Surface I.I-1.6 and 2.I.

Binding of anti-CHIPS $\triangle N / C \lg$ to CHIPS variants was determined by ELISA and is shown as \% binding to anti-CHIPS $\triangle N / C$ lgG in the table. Nine unique CHIPS variants with a maximum binding lower than $90 \%$ of wt CHIPS were found. These are marked in bold and were selected for further characterizations. In some positions no substitutions were made. This is marked by -

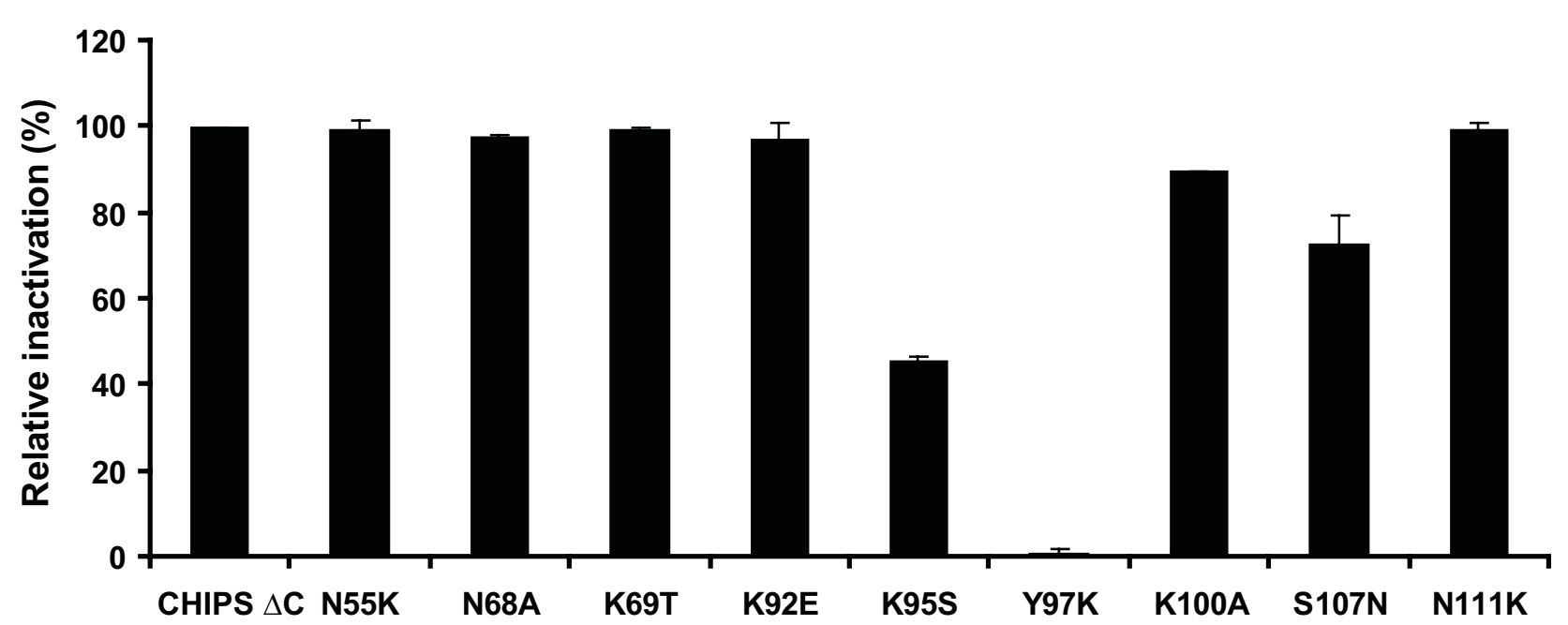

Figure 6

Inhibition of C5aR activity by CHIPS variants with C-terminal truncation. Fluo-3AM labeled U937/C5aR transfectants were preincubated with CHIPS variants and stimulated with $\mathrm{C} 5 \mathrm{a}$. Results are expressed as percentage inhibition of buffer treated cells. 


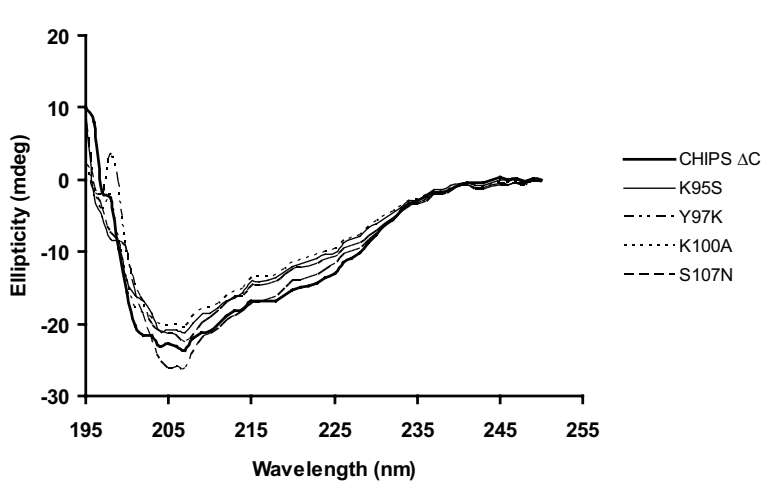

\section{Figure 7}

CHIPS with C-terminal truncation and selected corresponding mutants have the same overall structure. $C D$ spectra of C-terminally truncated CHIPS and variants with reduced $\mathrm{C} 5 \mathrm{aR}$ blocking activity, carrying one of the amino acid substitutions K95S, Y97K, KI00A or SI07N, were recorded. All CHIPS variants have a significant absorption minimum at $205 \mathrm{~nm}$ and are suggested to have the same overall structure as the corresponding wt protein.

did not affect the binding to the IgG. Surface 1.5 was another alternative epitope originating from the group 1 consensus sequence. This was the only linear epitope suggested, but the relevance of this surface was difficult to verify, since two of the five proposed residues (G70 and Y72) were not mutated. G70 and Y72 were considered important for maintaining the structure and were not mutated for stability reasons. Surface 2.1 was the only mapping possibility found for the group 2 consensus sequence. We consider this to be a less likely epitope, since mutagenesis of its amino acids did not reduce the antibody binding to a similar extent as that observed for 1.2 or 1.6.

During the mutational analysis for verification of antibody epitopes, amino acids involved in the interaction with the C5aR were also identified. The $\beta 3$ sheet is comprised of amino acids Y94-K100 and is most likely critical for binding to the C5aR since we show that substitutions K95S, Y97K and K100A as well as S107N affect the C5aR inhibiting activity of CHIPS, while leaving the CHIPS structure intact. These data confirm previous findings where the substitution K95A was implicated in C5aR blocking activity [25]. Some of the amino acid residues found to be important for the antibody interaction are therefore also most likely important for the receptor binding properties of CHIPS. This corroborates data from Wright et al. who recently showed that CHIPS-specific antibodies from human serum could inhibit the binding and activity of CHIPS to the C5aR [20].

The data about which amino acids are involved in C5aR binding is a finding that may be utilized in the design of an optimal CHIPS molecule that requires retained C5aR binding and blocking in addition to minimal binding of human antibodies. Our study suggests residues that must be left untouched or substituted in a more conservative manner. For certain applications, there may also be other aspects to consider, such as analysis of the presence of $\mathrm{T}$ cell epitopes. Such a process can be added in future studies when designing new CHIPS variants.

\section{Conclusion}

In conclusion, selection of peptide displaying phage libraries using a pool of CHIPS specific polyclonal human IgG resulted in the identification of peptide sequences that were mapped onto the CHIPS surface to form conformational antibody epitopes. These were verified by mutational analysis and at least two epitopes likely to be true epitopes were characterized. Amino acids important for C5aR binding within these epitopes were also identified by the mutagenesis. The mapping of human antibody epitopes on CHIPS is a step towards the development of an improved CHIPS molecule. Such a C5aR antagonist with low interaction with human IgG would potentially be an effective anti-inflammatory agent.

\section{Methods \\ Cloning, expression and purification of recombinant proteins}

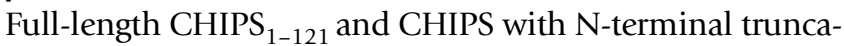
tion, composed of amino acids 31-121 (CHIPS $\Delta \mathrm{N}$ ) and CHIPS with $\mathrm{N}$ - and C-terminal truncations, composed of amino acids 31-113 (CHIPS $\Delta \mathrm{N} / \mathrm{C}$ ) were cloned, expressed and purified as described previously [27]. CHIPS with Cterminal truncation (CHIPS $\Delta \mathrm{C}$ ) and variants thereof were cloned in a modified pRSET B vector (Invitrogen, Carlsbad, CA). As a result of cloning, this protein was 112 amino acids long with two additional non-relevant amino acids included in the C-terminal end of the expressed protein. Cultivation was performed as described by Haas et al [27], but the protein was purified from inclusion bodies. Briefly, the CHIPS variants were purified from $E$. coli culture by lysis of the bacteria in $1 / 10$ culture volume binding buffer $(8 \mathrm{M}$ urea, $20 \mathrm{mM}$ Sodium Phosphate, $500 \mathrm{mM} \mathrm{NaCl}$, pH 7.8). After sonication and filtration, the lysate was loaded onto a HisTrap Ni-column (GE Healthcare, Uppsala, Sweden). The column was washed with binding buffer, $\mathrm{pH} 7.8, \mathrm{pH}$ 6.0 and $\mathrm{pH} 5.6$, respectively. CHIPS was eluted with binding buffer, pH 5.6 with $50 \mathrm{mM}$ EDTA and fractions containing protein as measured by $\mathrm{A}_{280}$ were pooled and refolded by dialysis against $50 \mathrm{mM}$ Tris- $\mathrm{HCl}, \mathrm{pH} 8.0$. The His-tag was removed as described [27].

\section{Site-directed mutagenesis and expression of CHIPS variants in plate format}

To be able to compare many mutants of truncated CHIPS, a tag is required to capture the proteins and determine relative concentrations. However, CHIPS activity has proven to be sensitive to the addition of His-tags in both the N- 
and C-terminus. These have to be cleaved off before functional assays can be performed. Instead, we used a mAb (2H7) recognition site located between residue 15 and 30 within the native CHIPS N-terminus that does not interfere with C5aR blocking activity [27]. Therefore the mutations were generated in CHIPS with C-terminal truncation, leaving the $\mathrm{N}$-terminal 30 amino acids untouched for recognition by the $2 \mathrm{H} 7 \mathrm{mAb}$ in ELISA. Sitedirected mutagenesis was performed in order to introduce point mutations into the CHIPS sequence with C-terminal truncation. This was performed using the QuikChange II mutagenesis kit (Stratagene, La Jolla, CA) according to the manufacturer's recommendations. The new CHIPS variants were sequence verified and transformed into $E$. coli BL-21 Star(DE3)pLysS (Invitrogen, Carlsbad, CA) for protein expression. Variants of CHIPS with C-terminal truncation were expressed in LB medium containing $50 \mu \mathrm{g} / \mathrm{ml}$ ampicillin and $34 \mu \mathrm{g} / \mathrm{ml}$ chloramphenicol in deep-well plates. Overnight cultures were diluted $1 / 50$ in fresh LB containing $50 \mu \mathrm{g} / \mathrm{ml}$ ampicillin and cultured at $37^{\circ} \mathrm{C}$ for 3 hours. IPTG (Isopropyl $\beta$-D-Thiogalactoside) (final concentration $0.5 \mathrm{mM})(\mathrm{BDH}$, Poole, UK) was added to logphase cultures to induce protein expression followed by cultivation for three hours. Protein was prepared from $E$. coli lysates by freeze-thawing the $E$. coli pellet in a buffer consisting of PBS-0.05\% Tween-20, Complete EDTA-free protease inhibitor (Roche, Basel, Switzerland), $25 \mathrm{U} / \mathrm{ml}$ Benzonase (Sigma-Aldrich, St Louis, MO) and $1 \mathrm{KU} / \mathrm{ml}$ rLysozyme (EMD Chemicals, Darmstadt, Germany). The lysates were incubated for $30 \mathrm{~min}$ at room temperature with shaking and centrifuged at 13,000 rpm for $15 \mathrm{~min}$ to remove debris and were stored at $-20^{\circ} \mathrm{C}$.

\section{Affinity purification of anti-peptide IgG and anti-CHIPS IgG}

A peptide, comprising the phage derived sequence MNKSYTI, was synthesized with an additional C-terminal spacer of three glycines and a cysteine for efficient coupling. (Bio-synthesis; Lewisville TX). A 38-mer peptide comprising the N-terminal part of CHIPS (first 37 amino acids plus an additional cysteine (Pepscan, Lelystad, The Netherlands) served as control. In order to couple the peptides to a solid matrix, peptides were first reduced using agarose linked Tris(2-Carboxyethyl) Phosphine (TCEP) (Pierce, Rockford, IL) and subsequently mixed with Sulfo-Link agarose beads (Pierce, Rockford, IL) in 50 $\mathrm{mM}$ Tris/HCl, pH 8,3 with $5 \mathrm{mM}$ EDTA for 2 hours at room temperature. Unreacted groups were blocked with L-cysteine and beads were extensively washed with coupling buffer and PBS. Small $1 \mathrm{ml}$ columns were used for affinity purification of IgG from a pooled human immunoglobulin preparation for intravenous use (IV-IgG) (Sanquin, Amsterdam, The Netherlands). IgG was eluted with $0.1 \mathrm{M}$ glycine-HCl buffer $\mathrm{pH} 2.9$ and neutralized with $1 \mathrm{M}$ Tris $\mathrm{pH}$ 8.0. Pooled fractions were dialyzed over- night against PBS and the purified anti-peptide IgG was stored at $4^{\circ} \mathrm{C}$.

Purified CHIPS variants (full-length or CHIPS $\Delta \mathrm{N} / \mathrm{C}$ ) were coupled to $\mathrm{CNBr}$ activated sepharose 4B (Amersham Biosciences, Uppsala, Sweden) and packed on a column according to manufacturer's instructions. Affinity purification was performed on an $\triangle$ KTA Prime system (Amersham Biosciences) according to the manufacturer's protocol. A total of $1 \mathrm{~g}$ IV-IgG $(20 \mathrm{mg} / \mathrm{ml})$ over the column. Bound human IgG was eluted with 0.1 M Glycine $\mathrm{pH} 3.0$ and the $\mathrm{pH}$ neutralized with $1 \mathrm{M}$ Tris, $\mathrm{pH}$ 8.0. Eluted fractions containing protein were pooled and buffer was changed to PBS on PD-10 columns (Amersham Biosciences). The affinity-purified human anti-CHIPS IgG was stored at $4{ }^{\circ} \mathrm{C}$.

\section{ELISA}

ELISA was used for many applications throughout the study. Nunc Maxisorb clear or white 96 well plates were coated with the specific protein in PBS. Incubations were carried out in a volume of $50 \mu \mathrm{l}$ for 1 hour at RT of not described differently, always followed by washing trice with PBS-0.05\%Tween-20. Dilution buffer for all reagents was PBS-0.05\%Tween-20 with 1\% BSA or milk powder added.

\section{Anti-CHIPS and Pepscan ELISA}

Microtiter plates were coated with CHIPS $(1 \mu \mathrm{g} / \mathrm{ml})$ overnight at $4{ }^{\circ} \mathrm{C}$. Plates were blocked with PBS-0.05\%Tween20 4\% BSA and incubated with different anti-CHIPS antibodies in dilution buffer with 1\% BSA. Bound antibodies were detected with goat- $\alpha$-human-IgG conjugated with peroxidase (Southern, Birmingham, USA) and TMB as substrate. For peptide experiments, synthetic 25-mer CHIPS derived peptides spanning the complete CHIPS $_{1-}$ ${ }_{121}$ sequence were synthesized as described earlier [27]. Plates were coated with peptide $(10 \mu \mathrm{M})$ overnight at $4^{\circ} \mathrm{C}$ and ELISA was performed as described above with IgG purified on full-length CHIPS $_{1-121}$.

\section{Binding of human anti-CHIPS $\triangle$ N/C IgG to CHIPS variants with C-terminal truncation}

For quantification of expressed proteins, plates were coated overnight at $4{ }^{\circ} \mathrm{C}$ with $3 \mu \mathrm{g} / \mathrm{ml}$ monoclonal anti$\mathrm{CHIPS} \mathrm{Ab} 2 \mathrm{H} 7$ directed against a peptide of CHIPS amino acids 24-30 [27]. Plates were blocked in PBS-0.05\% Tween-20 with 3\% milk powder, washed and incubated with serial dilutions of lysates from CHIPS variants in dilution buffer with $1 \%$ milk powder. Binding was detected with $3 \mu \mathrm{g} / \mathrm{ml}$ polyclonal rabbit anti-CHIPS N-terminal IgG (IgG produced by immunization of a rabbit with a KLH-coupled synthetic peptide corresponding to CHIPS N-terminal amino acids 1-14) and goat anti-rabbit IgG-HRP (Southern Biotech, Birmingham, AL)). Super 
Signal ELISA Pico Chemiluminescent Substrate (Pierce, Rockford, IL) was added and luminescence was measured.

For detection of binding of human anti-CHIPS IgG to the CHIPS variants, plates were coated, blocked and incubated with $E$. coli lysates as described above. Affinity-purified human anti-CHIPS $\Delta \mathrm{N} / \mathrm{C}$ IgG was added and binding was detected with goat-anti-human IgG HRP (Jackson ImmunoResearch, West Grove, PA) and substrate as described above.

\section{Random peptide phage libraries and phage selection}

The Ph.D.- $7^{\mathrm{TM}}$ and Ph.D.-C7C ${ }^{\mathrm{TM}}$ libraries from New England Biolabs (Ipswich, MA) were used to map the epitopes for human IgG on the surface of the CHIPS protein.

The Ph.D.- $7^{\mathrm{TM}}$ Phage Display Peptide library consists of 7mer random linear peptides fused with a linker sequence (GGGS) to the N-terminus of the major coat protein pIII of bacteriophage M13. The randomized segment of the Ph.D.-C7C ${ }^{\text {тм }}$ library is flanked by a pair of cysteine residues, which are oxidized during phage assembly to a disulfide linkage, resulting in the displayed peptides being presented to the target as loops [36]. Protein G coated beads $(100 \mu \mathrm{l})$ (Dynal, Norway) were washed three times with $1 \mathrm{ml}$ PBS-0.05\% Tween-20. The washed beads were blocked with $1 \mathrm{ml}$ PBS-0.05\% Tween-20, 5\% BSA for $1 \mathrm{~h}$ at $22^{\circ} \mathrm{C}$. Beads were washed four times and resuspended in $1 \mathrm{ml}$ PBS-0.05\% Tween-20. One half of the blocked beads was used for preclearing the phage stock. Therefore, $10 \mu \mathrm{l} \mathrm{Ph}$. D. $-7^{\mathrm{TM}}$ and $10 \mu \mathrm{l}$ Ph.D.-C7C $\mathrm{C}^{\mathrm{TM}}$ were incubated with blocked beads in PBS-0.05\% Tween-20 and were incubated for $30 \mathrm{~min}$ at $22^{\circ} \mathrm{C}$ under continuous agitation. Affinity-purified human anti-CHIPS $\triangle \mathrm{N} / \mathrm{C}$ IgG (final concentration $\sim 10 \mathrm{nM}$ ) was added to the precleared phages and incubated at $22^{\circ} \mathrm{C}$ for $30 \mathrm{~min}$. The phage/IgG suspension was added to the remaining blocked beads and incubated at $22^{\circ} \mathrm{C}$ for $30 \mathrm{~min}$. The beads were washed 10 times with PBS-0.05\% Tween-20 to wash away unbound phages. The bound phages were eluted with $0.2 \mathrm{M}$ Glycine, $\mathrm{pH} 2.2,0.1 \%$ BSA for $8 \mathrm{~min}$ followed by neutralization of the $\mathrm{pH}$ with $1 \mathrm{M}$ Tris- $\mathrm{HCl}, \mathrm{pH}$ 8. The eluate was amplified and $10 \mu \mathrm{l}$ of amplified phages was used as input for the next selection round. To increase the specificity of the phage selection, the bound phages in the fourth round were eluted using competition elution with the CHIPS protein. Bound phages were eluted by overnight incubation with $1.8 \mathrm{mg} / \mathrm{ml} \mathrm{CHIPS}$.

\section{Phage titration, amplification and characterization}

LB medium was inoculated with a single colony of ER2738 E. coli and incubated at $37^{\circ} \mathrm{C}$ with vigorous shaking until mid-log phase $\left(\mathrm{OD}_{600} \sim 0.5\right)$. Top agar $(50 \% \mathrm{LB}$ agar, 50\% LB medium) was melted and cooled to approximately $45^{\circ} \mathrm{C}$. Melted top agar $(3 \mathrm{ml})$ was added to $200 \mu \mathrm{l}$
ER2738 E. coli and poured on top of a LB/0.5 mM IPTG/ $80 \mu \mathrm{g} / \mathrm{ml}$ X-gal plate. $10 \mu \mathrm{l}$ of 10 -fold dilutions in LB medium was spotted on the prepared culture plates and incubated overnight at $37^{\circ} \mathrm{C}$. The next day, plaques were counted in order to calculate phage titers. The remaining phage eluate was added to ER2738 E. coli culture at early log phase $\left(\mathrm{OD}_{600} 0.4-0.5\right)$ and incubated with vigorous shaking at $37^{\circ} \mathrm{C}$ for $4.5 \mathrm{~h}$. Cultured cells were pelleted at $4^{\circ} \mathrm{C}$ and phages were precipitated overnight at $4{ }^{\circ} \mathrm{C}$ in 25\% PEG6000 (Sigma-Aldrich, St Louis, MO) $3 \mathrm{M} \mathrm{NaCl}$. The precipitated phages were centrifuged for $15 \mathrm{~min}$ at $10,000 \mathrm{rpm}, 4^{\circ} \mathrm{C}$. The pellet containing the amplified phages was resuspended in $200 \mu \mathrm{l}$ PBS and titrated as described above. After the fourth selection round no phage amplification was performed and phages were directly characterized by DNA sequencing.

48 different plaques from the titration plates were stabbed

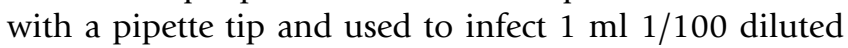
overnight culture of ER2738 E. coli and incubated for $4.5 \sim 5 \mathrm{~h}$ at $37^{\circ} \mathrm{C}$. Cultures were centrifuged and $500 \mu \mathrm{l}$ of the supernatant was precipitated with PEG6000, $3 \mathrm{M}$ $\mathrm{NaCl}$ for $10 \mathrm{~min}$ at $22^{\circ} \mathrm{C}$. The samples were centrifuged for $10 \mathrm{~min}$ at 13,600 $\mathrm{rpm}$ and the pellet was resuspended in $100 \mu \mathrm{l} 4 \mathrm{M} \mathrm{NaI}, 10 \mathrm{mM}$ EDTA, pH 8. $250 \mu \mathrm{l} 95 \% \mathrm{EtOH}$ was added and the samples were incubated for $10 \mathrm{~min}$ at $22^{\circ} \mathrm{C}$ to preferentially precipitate the single-stranded phage DNA. Samples were centrifuged for $10 \mathrm{~min}$ at 13,600 rpm and the pellet was washed with 70\% EtOH, dried and sent for sequencing to MWG Biotech (Martinsried, Germany) using the PIII-96seq primer (New England Biolabs, Ipswich, MA).

A phage ELISA was performed to test the binding specificity of the selected phages for affinity-purified human anti-CHIPS $\triangle \mathrm{N} / \mathrm{C}$ IgG. Affinity-purified human antiCHIPS $\triangle \mathrm{N} / \mathrm{C}$ IgG was coated overnight with at $4^{\circ} \mathrm{C}$. Coated and non-coated wells were blocked with PBS$0.05 \%$ Tween-20, 5\% BSA. Serial dilutions of the purified phage stocks in dilution buffer with $1 \%$ BSA were added and incubated for $1 \mathrm{~h}$ at $37^{\circ} \mathrm{C}$. Detection was performed with mouse anti-M13-mAb $(1 \mu \mathrm{g} / \mathrm{ml})$ (Amersham Biosciences, Uppsala, Sweden) and rabbit anti-mouse IgGHRP (Dako A/S, Glostrup, Denmark) and OPD substrate (O-phenylenediamine) (Sigma Aldrich, St Louis, MO).

\section{Analysis of peptide antibody binding to CHIPS}

Binding of affinity-purified antibodies and pooled human IgG (IV-IgG) to CHIPS was studied by ELISA as described for anti-CHIPS $\triangle \mathrm{N} / \mathrm{C}$ antibodies and by SPR on a Biacore 1000 instrument. $20 \mu \mathrm{l} 1 \mathrm{mg} / \mathrm{ml}$ CHIPS was directly coupled to an activated N-ethyl-N'(di-methylaminopropyl)carbodiimide (EDC) and N-hydroxysuccinimide (NHS) carboxymethyl dextran sensor chip (CM5). Unreacted groups were blocked by injection of $50 \mu \mathrm{l} 1 \mathrm{M}$ eth- 
anolamine- $\mathrm{HCl} \mathrm{pH} 8.5$. Binding assays were performed at a constant flow rate of $5 \mu \mathrm{l} / \mathrm{min}$ at $25^{\circ} \mathrm{C}$. Affinity-purified antibodies and IV-IgG were diluted in HBS-EP buffer (10 mM HEPES (pH 7.4) containing $150 \mathrm{mM} \mathrm{NaCl}, 3 \mathrm{mM}$ EDTA and $0.005 \%$ surfactant P20). Antibodies were allowed to interact with CHIPS for $210 \mathrm{~s}$ followed by a $120 \mathrm{~s}$ dissociation phase. Additionally, the antibodies were preincubated with $1 \mathrm{mg} / \mathrm{ml}$ CHIPS protein to study competition. Affinity-purified anti-peptide antibodies were tested at a concentration of $10 \mu \mathrm{g} / \mathrm{ml}$. Residual bound antibody was removed from the sensor chip surface by washing the chip for three minutes with $10 \mathrm{mM}$ glycine- $\mathrm{HCl}$ (pH 1.5).

\section{Epitope mapping}

The amino acid sequences of the selected phages were aligned using the Clustal-W alignment tool http:// www.ebi.ac.uk/clustalw/. Consensus sequences were manually mapped onto the surface of the CHIPS protein using the CHIPS ${ }_{31-121}$ NMR structure (PDB code: 1XEE) [25] and the PyMOL molecular graphics system [37].

\section{Biological activity assay}

The C5aR inhibiting capacity of the purified CHIPS variants with C-terminal truncation was tested by measuring calcium release from C5a stimulated U937 cells stably transfected with the C5aR [1]. U937 cells (human promonocytic cell line) transfected with the C5aR (U937/ $\mathrm{C} 5 \mathrm{aR}$ ) were a generous gift from Dr. E. Prossnitz (University of New Mexico, Albuquerque, NM). Cells were grown in $75 \mathrm{~cm}^{2}$ cell culture flasks in a $5 \% \mathrm{CO}_{2}$ incubator at $37^{\circ} \mathrm{C}$ and were maintained in RPMI 1640 medium with Lglutamine (Cambrex, Verviers, Belgium) and 10\% FBS (Cambrex, Verviers, Belgium). Briefly, $5 \times 10^{6} / \mathrm{ml}$ U937/ C5aR cells were incubated with $2 \mu \mathrm{M}$ Fluo-3AM (Sigma Aldrich, St Louis, MO) in RPMI 1640 medium with 0.05\% BSA for $30 \mathrm{~min}$ at room temperature. After washing, the cells were preincubated with buffer or a 3-fold dilution series of CHIPS variants ( 1 to $0.003 \mu \mathrm{g} / \mathrm{ml}$ ) at room temperature for $30 \mathrm{~min}$. Every sample was measured on a FACSsort flow cytometer (BD Biosciences, San José, CA) and C5a (Sigma Aldrich, St Louis, MO) (final concentration $1 \mathrm{nM}$ ) was added. The cell population was gated on forward and side scatter and results are expressed as percentage inhibition of calcium release as compared to cells without addition of CHIPS.

\section{CD spectroscopy}

The structures of the purified C-terminally truncated CHIPS variants were compared by the use of CD spectroscopy. The experiment was carried out on a Jasco J-720 spectropolarimeter (Jasco Inc., Easton, MD) in a $2 \mathrm{~mm}$ cuvette at a protein concentration of $\sim 20 \mu \mathrm{M}$. Spectra were recorded from 195 to $250 \mathrm{~nm}$ at $20^{\circ} \mathrm{C}$, at a scan speed 50 $\mathrm{nm} / \mathrm{min}$, a time constant of $4 \mathrm{~s}$, a bandwidth of $1 \mathrm{~nm}$, resolution of $1 \mathrm{~nm}$ and sensitivity of $50 \mathrm{mdeg}$.

\section{Data analysis}

Data from ELISA and cellular experiments were plotted by the use of the Prism 4 software package (GraphPad Software Inc.). The cellular data were fitted in a nonlinear regression model (sigmoidal dose-response curve with variable slope).

\section{Abbreviations}

CHIPS: Chemotaxis inhibitory protein of Staphylococcus aureus; C5a: complement fragment C5a; C5aR: C5a receptor; FPR: Formylated peptide receptor; Wt: Wild-type; SPR: Surface Plasmon Resonance.

\section{Authors' contributions}

EG carried out the mutational analysis, functional assays and structural comparisons, participated in the design of the study and purification of antibodies and drafted the manuscript. PJH carried out the phage selections and pepscan experiments and participated in the design of the study and the epitope mapping and drafted the manuscript. BW carried out the epitope mapping and participated in the design of the study and helped to draft the manuscript. MH carried out the SPR measurements. CF participated in the design of the study and helped to draft the manuscript. MO participated in the design of the study and helped to draft the manuscript. JvS participated in the design of the study. KvK participated in the design of the study, purification of antibodies and draft of the manuscript. All authors read and approved the final manuscript.

\section{Additional material}

\section{Additional file 1}

Additional table 1. Additional table 1 shows the residue - residue distances (A) between proposed epitopes.

Click here for file

[http://www.biomedcentral.com/content/supplementary/1471-

2172-10-13-S1.doc]

\section{Acknowledgements}

We thank Cecilia Forsberg, Karin Haraldsson, Anna Rosén and Stina Lindman for excellent technical support. The study was supported by grants from the Swedish Research Council and the European Commission (MTKICT-2004-5 I7I28).

\section{References}

I. De Haas Cl, Veldkamp KE, Peschel A, Weerkamp F, Van Wamel W], Heezius EC, Poppelier MJ, Van Kessel KP, Van Strijp JA: Chemotaxis Inhibitory Protein of Staphylococcus aureus, a Bacterial Antiinflammatory Agent. J Exp Med 2004, 199:687-695.

2. Postma B, Poppelier MJ, van Galen JC, Prossnitz ER, van Strijp JA, de Haas CJ, van Kessel KP: Chemotaxis inhibitory protein of Staphylococcus aureus binds specifically to the $\mathrm{C5a}$ and formylated peptide receptor. J Immunol 2004, 172:6994-700I.

3. Goldstein IM, Weissmann G: Generation of C5-derived lysosomal enzyme-releasing activity ( $\mathrm{C5a}$ ) by lysates of leukocyte lysosomes. J Immunol 1974, I I 3: I 583-1588. 
4. Sacks T, Moldow CF, Craddock PR, Bowers TK, Jacob HS: Oxygen radicals mediate endothelial cell damage by complementstimulated granulocytes. An in vitro model of immune vascular damage. J Clin Invest 1978, 61: | |61-| I67.

5. Marder SR, Chenoweth DE, Goldstein IM, Perez HD: Chemotactic responses of human peripheral blood monocytes to the complement-derived peptides $\mathbf{C 5 a}$ and $\mathbf{C 5}$ a des Arg. J Immunol 1985, I 34:3325-3331.

6. Guo RF, Ward PA: Role of C5a in inflammatory responses. Annu Rev Immunol 2005, 23:82 I-852.

7. Hopkins P, Belmont HM, Buyon J, Philips M, Weissmann G, Abramson $\mathrm{SB}$ : Increased levels of plasma anaphylatoxins in systemic lupus erythematosus predict flares of the disease and may elicit vascular injury in lupus cerebritis. Arthritis Rheum 1988, 3I:632-64I.

8. Huber-Lang M, Sarma VJ, Lu KT, McGuire SR, Padgaonkar VA, Guo RF, Younkin EM, Kunkel RG, Ding J, Erickson R, Curnutte JT, Ward PA: Role of C5a in multiorgan failure during sepsis. J Immunol 2001, 166:1193-1199.

9. Neumann E, Barnum SR, Tarner IH, Echols J, Fleck M, Judex M, Kullmann F, Mountz JD, Scholmerich J, Gay S, Muller-Ladner U: Local production of complement proteins in rheumatoid arthritis synovium. Arthritis Rheum 2002, 46:934-945.

10. Grant EP, Picarella D, Burwell T, Delaney T, Croci A, Avitahl N, Humbles AA, Gutierrez-Ramos JC, Briskin M, Gerard C, Coyle AJ: Essential role for the $\mathrm{C5}$ a receptor in regulating the effector phase of synovial infiltration and joint destruction in experimental arthritis. J Exp Med 2002, 196:146|-|47|.

II. Woodruff TM, Arumugam TV, Shiels IA, Reid RC, Fairlie DP, Taylor $S M$ : A potent human C5a receptor antagonist protects against disease pathology in a rat model of inflammatory bowel disease. J Immunol 2003, I7 I:55 I4-5520.

12. Arumugam TV, Shiels IA, Woodruff TM, Granger DN, Taylor SM: The role of the complement system in ischemia-reperfusion injury. Shock 2004, 2 I:40I-409.

13. Rittirsch D, Flierl MA, Nadeau BA, Day DE, Huber-Lang M, Mackay CR, Zetoune FS, Gerard NP, Cianflone K, Kohl J, Gerard C, Sarma JV, Ward PA: Functional roles for $\mathrm{C5a}$ receptors in sepsis. Nat Med 2008, 14:55I-557.

14. Konteatis ZD, Siciliano SJ, Van Riper G, Molineaux C], Pandya S, Fischer P, Rosen H, Mumford RA, Springer MS: Development of C5a receptor antagonists. Differential loss of functional responses. J Immunol 1994, I 53:4200-4205.

15. Heller T, Hennecke M, Baumann U, Gessner JE, zu Vilsendorf AM, Baensch M, Boulay F, Kola A, Klos A, Bautsch W, Kohl J: Selection of a $\mathrm{C5}$ a receptor antagonist from phage libraries attenuating the inflammatory response in immune complex disease and ischemia/reperfusion injury. J Immunol 1999, 163:985-994.

16. Riley RD, Sato H, Zhao ZQ, Thourani VH, Jordan JE, Fernandez AX, Ma XL, Hite DR, Rigel DF, Pellas TC, Peppard J, Bill KA, Lappe RW, Vinten-Johansen J: Recombinant human complement C5a receptor antagonist reduces infarct size after surgical revascularization. J Thorac Cardiovasc Surg 2000, 120:350-358.

17. Strachan AJ, Woodruff TM, Haaima G, Fairlie DP, Taylor SM: A new small molecule C5a receptor antagonist inhibits the reversepassive Arthus reaction and endotoxic shock in rats. J Immunol 2000, 164:6560-6565.

18. Woodruff TM, Strachan AJ, Dryburgh N, Shiels IA, Reid RC, Fairlie DP, Taylor SM: Antiarthritic activity of an orally active C5a receptor antagonist against antigen-induced monarticular arthritis in the rat. Arthritis Rheum 2002, 46:2476-2485.

19. Huber-Lang MS, Riedeman NC, Sarma JV, Younkin EM, McGuire SR, Laudes IJ, Lu KT, Guo RF, Neff TA, Padgaonkar VA, Lambris JD, Spruce L, Mastellos D, Zetoune FS, Ward PA: Protection of innate immunity by C5aR antagonist in septic mice. Faseb J 2002, 16:1567-1574

20. Wright A], Higginbottom A, Philippe D, Upadhyay A, Bagby S, Read RC, Monk PN, Partridge LJ: Characterisation of receptor binding by the chemotaxis inhibitory protein of Staphylococcus aureus and the effects of the host immune response. Mol Immunol 2007, 44:2507-25I7.

21. Rowley MJ, O'Connor K, Wijeyewickrema L: Phage display for epitope determination: a paradigm for identifying receptorligand interactions. Biotechnol Annu Rev 2004, 10:151-188.

22. Scott JK, Smith GP: Searching for peptide ligands with an epitope library. Science 1990, 249:386-390.
23. Luzzago A, Felici F, Tramontano A, Pessi A, Cortese R: Mimicking of discontinuous epitopes by phage-displayed peptides, I. Epitope mapping of human $\mathrm{H}$ ferritin using a phage library of constrained peptides. Gene 1993, I 28:5I-57.

24. Rowley MJ, Scealy M, Whisstock JC, Jois JA, Wijeyewickrema LC, Mackay IR: Prediction of the immunodominant epitope of the pyruvate dehydrogenase complex E2 in primary biliary cirrhosis using phage display. J Immunol 2000, 164:34I3-3419.

25. Haas PJ, de Haas C], Poppelier MJ, van Kessel KP, van Strijp JA, Dijkstra K, Scheek RM, Fan H, Kruijtzer JA, Liskamp RM, Kemmink J: The structure of the C5a receptor-blocking domain of chemotaxis inhibitory protein of Staphylococcus aureus is related to a group of immune evasive molecules. I Mol Biol 2005, 353:859-872.

26. Gustafsson E, Forsberg C, Haraldsson K, Lindman S, Ljung L, Furebring C: Purification of truncated and mutated Chemotaxis Inhibitory Protein of Staphylococcus aureus - an anti-inflammatory protein. Protein Expr Purif 2009, 63:95-101.

27. Haas PJ, de Haas CJ, Kleibeuker W, Poppelier MJ, van Kessel KP, Kruijtzer JA, Liskamp RM, van Strijp JA: N-terminal residues of the chemotaxis inhibitory protein of Staphylococcus aureus are essential for blocking formylated peptide receptor but not C5a receptor. J Immunol 2004, I 73:5704-57II.

28. Cook AD, Davies JM, Myers MA, Mackay IR, Rowley MJ: Mimotopes identified by phage display for the monoclonal antibody CIICI to type II collagen. J Autoimmun 1998, I I:205-2 I I.

29. Davies JM, Cai YP, Weir RC, Rowley MJ: Characterization of epitopes for virus-neutralizing monoclonal antibodies to Ross River virus E2 using phage-displayed random peptide libraries. Virology 2000, 275:67-76.

30. Osman AA, Uhlig H, Thamm B, Schneider-Mergener J, Mothes T: Use of the phage display technique for detection of epitopes recognized by polyclonal rabbit gliadin antibodies. FEBS Lett 1998 , 433: $103-107$.

3I. Ikuno N, Scealy M, Davies JM, Whittingham SF, Omagari K, Mackay IR, Rowley MJ: A comparative study of antibody expressions in primary biliary cirrhosis and autoimmune cholangitis using phage display. Hepatology 200I, 34:478-486.

32. Peters EA, Schatz PJ, Johnson SS, Dower W]: Membrane insertion defects caused by positive charges in the early mature region of protein pIII of filamentous phage fd can be corrected by prlA suppressors. J Bacteriol 1994, I 76:4296-4305.

33. Smith GP, Petrenko VA: Phage Display. Chem Rev 1997, 97:391-410

34. Jin L, Fendly BM, Wells JA: High resolution functional analysis of antibody-antigen interactions. J Mol Biol 1992, 226:85I-865.

35. Geysen HM, Mason T], Rodda SJ: Cognitive features of continuous antigenic determinants. I Mol Recognit 1988, I:32-4I.

36. McLafferty MA, Kent RB, Ladner RC, Markland W: MI3 bacteriophage displaying disulfide-constrained microproteins. Gene 1993, I 28:29-36.

37. DeLano WL: The PyMOL Molecular Graphics System. 2008 [http://pymol.sourceforge.net/overview/index.htm]. Palo Alto, CA: Delano Scientific LLC

\section{Publish with Bio Med Central and every} scientist can read your work free of charge

"BioMed Central will be the most significant development for disseminating the results of biomedical research in our lifetime. "

Sir Paul Nurse, Cancer Research UK

Your research papers will be:

- available free of charge to the entire biomedical community

- peer reviewed and published immediately upon acceptance

- cited in PubMed and archived on PubMed Central

- yours - you keep the copyright
BioMedcentral 